\title{
OPEN NETWORK FOR LOCAL SELF SUSTAINABILITY, BOOSTING BIOREGIONAL DEVELOPMENT THROUGH AN OPEN DATA SHARING SYSTEM
}

\author{
M. Clementi ${ }^{a^{*}}$, C. Fontana ${ }^{b}$, A. Rogora ${ }^{\mathrm{c}}$ \\ a Dept. of Architecture and Urban Studies, Politecnico di Milano, Milano, Italy - matteo.clementi@polimi.it \\ ${ }^{\mathrm{b}}$ Dept. of Architecture and Uban Studies, Politecnico di Milano, Milano, Italy - carlotta.fontana@polimi.it \\ c Dept. of Architecture and Uban Studies, Politecnico di Milano, Milano, Italy - alessandro.rogora@polimi.it
}

\section{Commission IV, WG IV/4}

KEY WORDS: Self sustainability, Spatial Data Sharing Systems, geo-referenced LCA data

\begin{abstract}
:
The paper presents an online geodatabase currently under development. Its name is Open NETwork for Local Self Sustainability and the website address is www.oloss.net.The goal of this platform is to publish and share information about production and consumption chain oriented towards the use of locally available resources. To this end, it provides an open standard of supply chains georeferenced representation, and the ability to georefer data generally used in the context of life cycle analysis of products and services. This standard has the purpose of representing production and consumption chains in the form of Impact Geographies (IGs). This database may provide public administration centers, research centers, NGOs, planners and designers with information useful to develop projects geared towards the optimal use of local resources, consistent with the bioregional development paradigm (Sale, 1985) (Scudo, 2016). The bioregional approach promotes trans-scalar regional supply and demand chains where food and energy are grown, produced, sold and consumed within a certain territorial unit.
\end{abstract}

\section{INTRODUCTION}

\subsection{Goals}

The database presented in the paper has been created as an integral part of an analysis and design methodology, which allows directing the choices towards local self-sustainability scenarios on different scales, in coherence with the application of the bioregional development paradigm. The possibilities of meeting renewable supply and local demand, which characterize its general lines, involve the orientation of the flows activated by the demand towards the resources available locally.

This strategy is divided into two main macro-phases: first of all the increase in efficiency in the management of energy and materials and then the orientation of local demand towards locally available renewable resources.

The technology is now mature to provide real solutions to the development of self-sustainability scenarios. Open source GIS (like QGIS or GRASS, https://www.osgeo.org ) offer a valid support to learn about the characteristics of a territory, in particular, the specificities of its natural and built environment (Clementi, 2013). In order to elaborate and diffuse adequate solutions towards environmental sustainability scenarios, open and adequate georeferenced data to be managed by local actors are lacking.

\subsection{To whom it is addressed}

The combination of environmental and economic sustainability, that characterizes local self-sustainable development, presupposes a widespread involvement of local actors and consequently assigns to the public administrative units a fundamental role in the promotion and management of these transition initiatives.
This database is aimed primarily at municipalities, groups of them and local actors working in the context of the built environment the transformation and land planning, from the designer to the final user (the inhabitant). In particular, attention is paid to minor municipalities and groupings of these, in which it is easier to trigger activities aimed at local self-sustainability and bioregional development through the direct involvement of settled communities.

The tools presented in the text lay the foundations of an opensource information system aimed at the entire community operating on a specific territory, it will be promoted and managed by the public administration with the aim of reducing the environmental impacts of local consumption dynamics and reconnecting workforce and territory.

It is aimed at any type of settled community, "high or low economic realities". At present data it refers to the Italian context, but being the database open and implementable by anyone, its applicability to different contexts depends on the level of implementation of geoferenced good practices in the database. The structure of the geo-referenced data and the adopted indicators have been chosen to facilitate implementation by different disciplinary area. It allows the interaction between different professionals who share a common goal: To orient the consumption choices of the inhabitants towards sustainable local productions.

\subsection{Self sufficiency Scenario using Gis}

The current development of gis opensource and open data in estimating renewable energy potential allow an effective mapping of the local renewable supply and renewable energy potential (PRL in figure 1 and 2), building up effective Resources Geographies. In order to set the basics for open and free tools to develop self-sufficiency scenarios, OLOSS wants

Corresponding author 
to provide useful information in order to assess and represent local energy and material demand (DLEM in figure 1 and 2).

Being able to access the same GIS project data on the supply and demand it is possible to develop ameliorative scenarios oriented towards local self-sufficiency.

The potential offered by the current state of development of GIS Opensource (GRASS and QGIS in particular) assume the role of operational tools in the project, in order to define improvement scenarios. The graphical tool useful for this purpose is represented by the Impact Geographies, IGs, that can be consulted, downloaded and implemented on www.oloss.net.

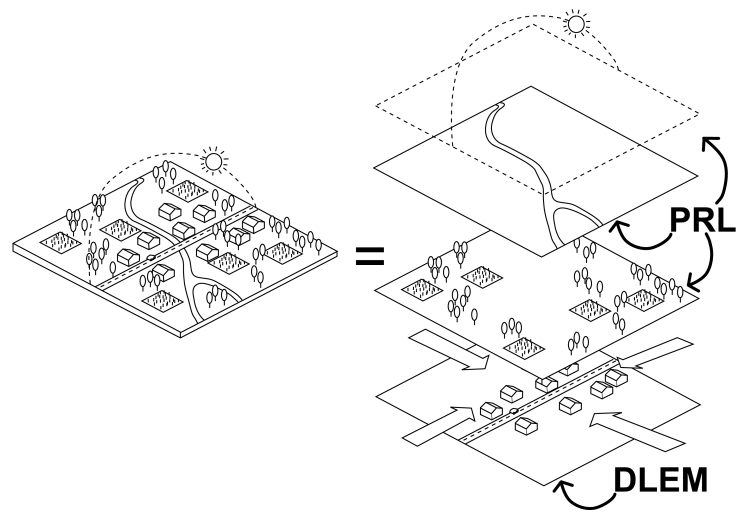

Figure 1. Data on local renewable potential (PRL) and local energy and matter demand (DLEM) can be managed in the same GIS project

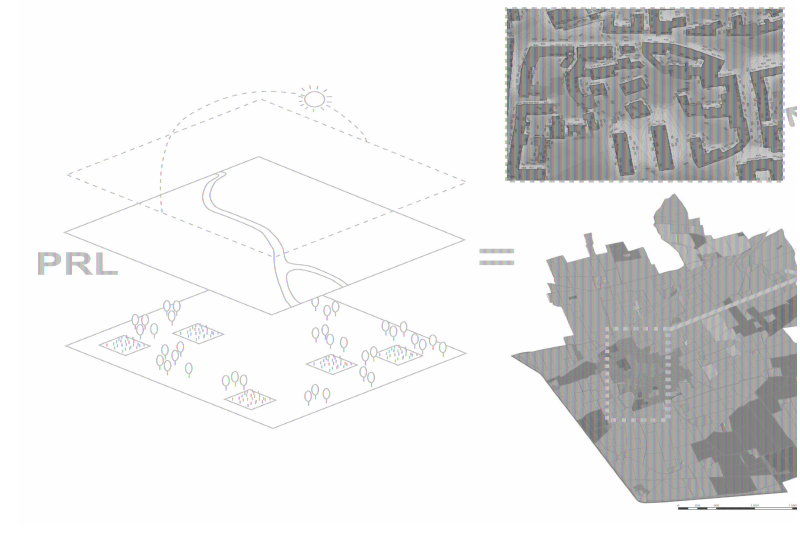

Figure 2. Some Resources Geographies that make up the local renewable potential, solar energy maps and biomass availability maps

\section{OLOSS DATABASE}

\subsection{Introductory notes on the oloss.net platform}

At its initial stage, the website will host information about the architecture of each Inpact Geography (IG), providing the basis for an implementable representation standard of georeferenced lca data. The different chains will be divided into the main consumption categories that constitute the environmental impacts of an average user: housing, food, transport.
Following the same way of articulating and representing data, IG processing enables to represent supply chains related to different fields of expertise.

\subsection{Starting from the supply chains representative of an inhabitant's lifestyle}

At its mature state of development, the database will include 43 types of supply chains, divided into 4 categories: housing, food, transport, waste. These categories have been chosen because they represent the main impacts of the average inhabitant. They make up the environmental profile of an inhabitant's lifestyle, with the exception of services and other consumer activities. In this way they allow mapping the main consumption activities of a community located in a territory, assessing its environmental impacts and developing improvement scenarios by adopting widespread and good practices from the database and transferring them to the context in which the scenario will be developed.

The 43 types of supply chains are organized as follows:

The housing category contains two further cathegories: housing use and housing materials.

The category of the housing use phase contains 4 types of supply chains: energy for heating, energy for hot water, energy for cooking, electricity.

The category of the production phase of the buildings materials is divided into: foundations, vertical structures, horizontal structures, external walls, windows, floors, roofs, systems.

The food category is divided into subcategories such as: Grain and grain based products: bread, pasta, rice, flours. Vegetables: fruiting vegetables, leaf vegetables, root vegetables, bulb vegetables

Tubers: patatoes

Legumes: dried beans

Fruit: pome fruits, citrus fruits, stone fruits

Meat: beef, pork, poultry meat

Fish: frozen fish

Milk and dairy products: milk, cheese

Eggs and egg products: eggs

Animal and vegetable oils: olive oil

The transport categoru takes into account the private transport.

The category of waste is currently related to solid urban waste in the residential sector and is made up of 9 types of waste: unsorted waste, paper waste, plastic waste, metal waste, glass waste, organic waste, green waste, wood waste, clothing waste. For each type of supply chain it will be possible to download multiple Impact Geographies, depending on the level of implementation of that type of supply chain by the community. In the case, for example, of the type concerning bread the database is actually populated with two supply chain: one representative of the common practice in Italy and a good practice on the local production of organic bread (in the Po valley in northern Italy). In the future the same category can include IGs related to other good practices and common practices related to other contexts. They can be characterized by different climatic conditions, on fiels yields and energy mixes.

\subsection{Impact Geographys, IGs}

Impact Geographies (IGs) are characterized by a common structure consisting of georeferenced vectors representative o the main supply chain phases of a general product. By supply chain we mean the entire life cycle of a material or energy product, from production / extraction, to consumption and to the end of life of any kind of waste associated with the same chain. 
In particular, the information associated to each supply chain are divided into two distinct layers (shapefile), the layer of the supply chain nodes and the layer of the connections between them.

The first consists of points, which are associated with the quantities of energy and matter used in the main production / consumption phases (ie the set of activities related to the supply chain that take place in the same place), Figure 3.

The second, consisting of lines connecting the points, associates to the vectors information concerning the transport of the material from one node to another (modes, quantities, distances), Figure 4.

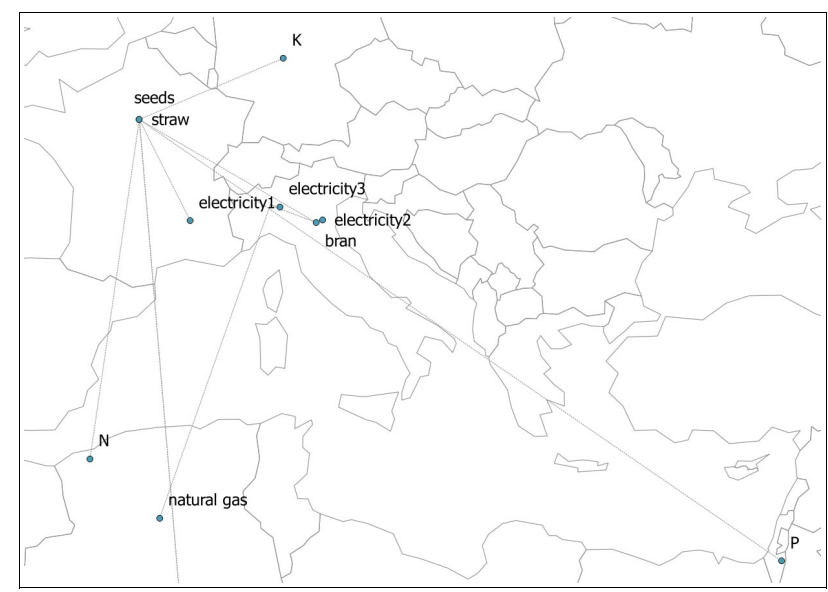

Figure 3. Nodes (points) mapped in an IG of a bread supply chain, average italian practice

\begin{tabular}{|c|c|c|c|c|c|c|c|c|}
\hline 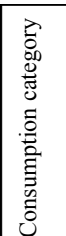 & 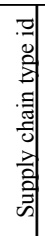 & 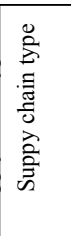 & 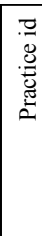 & 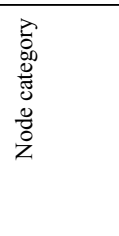 & 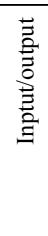 & 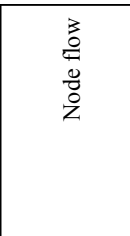 & 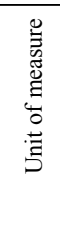 & 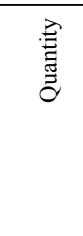 \\
\hline food & 7 & bread & 1 & $\begin{array}{l}\text { seed } \\
\text { production }\end{array}$ & in & seeds & $\mathrm{kg}$ & 0,0290 \\
\hline food & 7 & bread & 1 & $\begin{array}{l}\text { fertilizer } \\
\text { production }\end{array}$ & in & $\mathrm{N}$ & $\mathrm{kg}$ & 0,0220 \\
\hline food & 7 & bread & 1 & $\begin{array}{l}\text { fertilizer } \\
\text { production }\end{array}$ & in & $\mathrm{P}$ & $\mathrm{kg}$ & 0,0110 \\
\hline food & 7 & bread & 1 & $\begin{array}{l}\text { fertilizer } \\
\text { production }\end{array}$ & in & $\mathrm{K}$ & $\mathrm{kg}$ & 0,0110 \\
\hline food & 7 & bread & 1 & $\begin{array}{l}\text { field } \\
\text { production }\end{array}$ & in & $\begin{array}{l}\text { diesel fuel } \\
\end{array}$ & $\mathrm{kg}$ & 0,0150 \\
\hline food & 7 & bread & 1 & $\begin{array}{l}\text { field } \\
\text { production }\end{array}$ & in & \begin{tabular}{|l|} 
lubricating \\
oil
\end{tabular} & $\mathrm{kg}$ & 0,0003 \\
\hline food & 7 & bread & 1 & $\begin{array}{l}\text { field } \\
\text { production }\end{array}$ & in & \begin{tabular}{|l|} 
electricity \\
\end{tabular} & kWh & 0,0001 \\
\hline food & 7 & bread & 1 & $\begin{array}{l}\text { field } \\
\text { production }\end{array}$ & out & straw & $\mathrm{kg}$ & 0,8750 \\
\hline food & 7 & bread & 1 & $\begin{array}{l}\text { flour } \\
\text { production }\end{array}$ & in & \begin{tabular}{|l|} 
electricity \\
\end{tabular} & $\mathrm{kWh}$ & 0,0700 \\
\hline food & 7 & bread & 1 & $\begin{array}{l}\text { flour } \\
\text { production }\end{array}$ & out & bran & $\mathrm{kg}$ & 0,0800 \\
\hline food & 7 & bread & 1 & baking & in & electricy3 & $\mathrm{kWh}$ & 0,0200 \\
\hline food & 7 & bread & 1 & baking & in & natural gas & $\mathrm{m}^{3}$ & 0,0830 \\
\hline
\end{tabular}

Table 1. Some of the data associated with the IG nodes of a bread supply chain, average italian practice (data refer to $1 \mathrm{~kg}$ of bread)

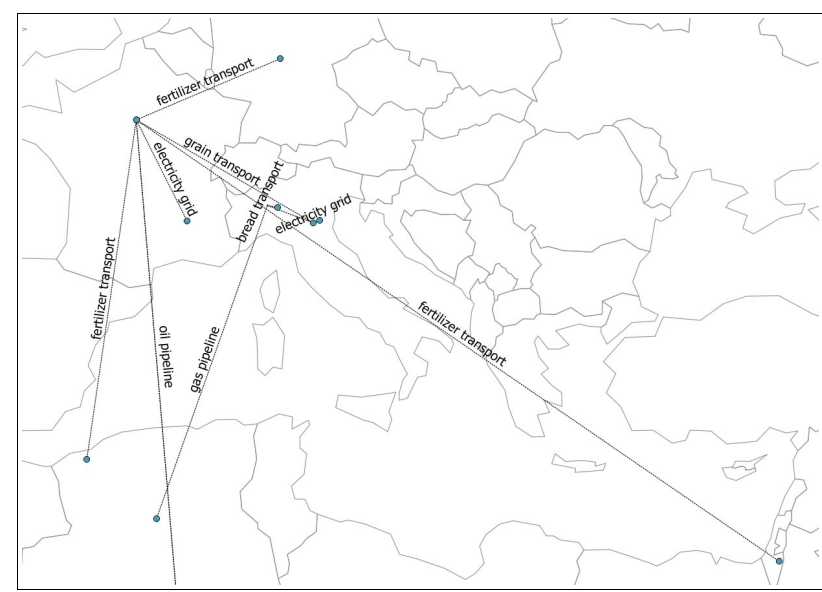

Figure 4. Connections (lines) mapped in an IG of a bread supply chain, average italian practice

\begin{tabular}{|c|c|c|c|c|c|c|c|c|}
\hline 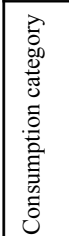 & 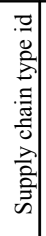 & 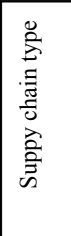 & 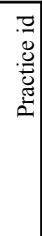 & 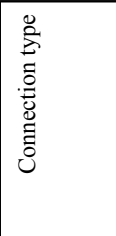 & 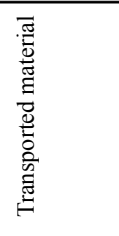 & 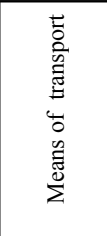 & 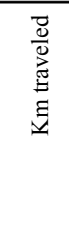 & 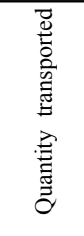 \\
\hline food & 7 & bread & 1 & $\begin{array}{l}\text { fertilizer } \\
\text { transport }\end{array}$ & $\mathrm{N}$ & \begin{tabular}{|l|}
$28 \mathrm{t}$ truck \\
\end{tabular} & 1550 & 0,0220 \\
\hline food & 7 & bread & 1 & $\begin{array}{l}\text { fertilizer } \\
\text { transport }\end{array}$ & $\mathrm{P}$ & 28t truck & 3400 & 0,0110 \\
\hline food & 7 & bread & 1 & $\begin{array}{l}\text { fertilizer } \\
\text { transport }\end{array}$ & $\mathrm{K}$ & $28 \mathrm{t}$ truck & 590 & 0,0110 \\
\hline food & 7 & bread & 1 & $\begin{array}{l}\text { Oil } \\
\text { pipeline }\end{array}$ & diesel fuel & - & - & 0,0150 \\
\hline food & 7 & bread & 1 & $\begin{array}{l}\text { Oil } \\
\text { pipeline }\end{array}$ & $\begin{array}{l}\text { lubricatin } \\
\text { g oil }\end{array}$ & - & - & 0,0003 \\
\hline food & 7 & bread & 1 & $\begin{array}{l}\text { electricity } \\
\text { grid }\end{array}$ & $\begin{array}{l}\text { electricity } \\
1\end{array}$ & grid & - & 0,0001 \\
\hline food & 7 & bread & 1 & $\begin{array}{l}\text { grain } \\
\text { transport }\end{array}$ & grain & $28 \mathrm{t}$ truck & 1000 & 0,8750 \\
\hline food & 7 & bread & 1 & $\begin{array}{l}\text { electricity } \\
\text { grid }\end{array}$ & $\begin{array}{l}\text { electricity } \\
2\end{array}$ & grid & - & \\
\hline food & 7 & bread & 1 & $\begin{array}{l}\text { flour } \\
\text { transport }\end{array}$ & flour & $16 \mathrm{t}$ truck & 150 & 0,7000 \\
\hline food & 7 & bread & 1 & $\begin{array}{l}\text { electricity } \\
\text { grid }\end{array}$ & $\begin{array}{l}\text { electricity } \\
3\end{array}$ & grid & - & \\
\hline food & 7 & bread & 1 & $\begin{array}{l}\text { Gas } \\
\text { pipeline }\end{array}$ & $\begin{array}{l}\text { Natural } \\
\text { gas }\end{array}$ & pipeline & - & \\
\hline food & 7 & bread & 1 & $\begin{array}{l}\text { bread } \\
\text { transport }\end{array}$ & bread & $16 \mathrm{t}$ truck & 30 & 1,0000 \\
\hline
\end{tabular}

Table 2. Some of the data associated with the IG connections of a bread supply chain, average italian practice (data refer to $1 \mathrm{~kg}$ of bread)

\subsection{Reference functional units}

Each IG is associated with a unitary quantity of material / energy flow. For example, in the case of the dynamics linked to food consumption it refers to one $\mathrm{kg}$ of product, in the case of electricity consumption in the home to one $\mathrm{kWh}$. The connection lines between the nodes contain useful information for the calculation of energy consumption due to transport, the kilometers traveled, the mode of transport, the amount of energy used to move $1 \mathrm{~kg}$ of product of $1 \mathrm{~km}$ (this breakdown of the data is useful to recalculate distances in case of practice transfer in the development of scenarios.)

The adoption of reference functional units based on product unitary values makes it possible to use each IG for the mapping of community consumption established in different territorial 
areas. Depending on whether it is a building, a district, or an aggregation of several municipalities, this can happen by associating the data in the IG to the estimated annual consumption quantity for the local context.

This arrangement allows an easy comparison between supply chain practices within the same category, and enable to direct the choice among them according to the specific goals of each scenario.

\subsection{Indicators}

The quantities of energy and matter associated with the characteristic activities of the supply chain nodes and the transport modes that connect them, are associated with specific impact indicators useful to assess the sustainability of the activity.The current level of development of the database adopts the following indicators:

- NRE: accounting of non-renewable primary energy, expressed in MJ, accounts for the energy consumption, bringing back all the processes to their primary source of non-renewable energy, accounted on the basis of the higher calorific value.

- RE: accounting of renewable primary energy, it is expressed in MJ. It take into consideration all biomass combustion processes using the higher calorific value, and the solar energy production processes accounting for the usable amount of energy or heat (for example MJ of electricity produced by a photovoltaic system). Those information provide the possibility of assessing the sustainability of such activities, comparing the amount of local renewable energy used to nonrenewable one.

- TP: the accounting of productive land, expressed in square meters, measures the extent of local productive land useful for the production in the field of the materials associated with the supply chain nodes, or the amount of built land with an high solar energy potential, used for to produce energy. This indicator expresses the amount of land involved in the production of energy and matter. The greater is the use of renewable energy in the entire supply chain, the greater will be the importance of this indicator. Considering two supply chains characterized by the same amount of renewable energy used, the user will choose the one that involves a lower productive land or in any case a category of productive land that is sufficiently present in the local context.

- MP: local manpower, expressed in man-hours required to perform the activities associated with each node and transport between the nodes. Accounting workforce activated by the supply chain lays the foundations for socioeconomic assessments oriented to local development.

\subsection{Examples}

The consumption flows relating to the energy supply chain for winter heating in housing and bread in the categories of food are taken as examples. The maps refer to an area of the province of Milan named Magentino-Abbiantense, composed of multiple municipalities.

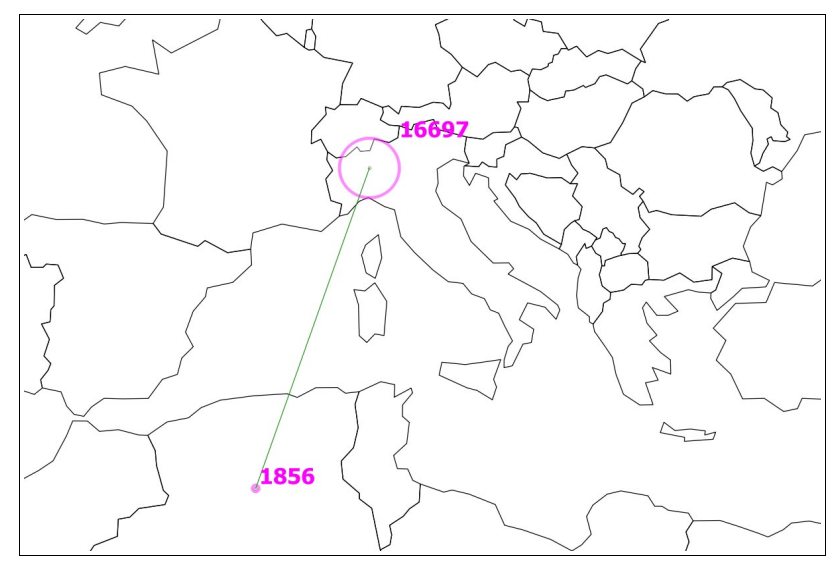

Figure 5. IG of natual gas supply chain for housing heating. The nodes map the amount of non-renewable primary energy used per person in a year. MJ / person * year (Magentino-Abbiatense context)

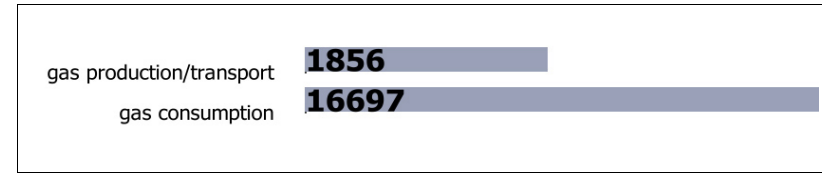

Figure 6. Amount of non-renewable primary energy associated with the natural gas supply chain nodes for housing heating,

$\mathrm{MJ} /$ person * year (Magentino-Abbiatense context)

The IGs in the Figures (5-9) illustrate the different amount of primary energy associated with the activities of the supply chain through circles of different diameters. The different color refers to the type of energy (non-renewable magenta and renewable green). In particular, each node includes the amount of energy used for the production of materials involved and the direct energy use.

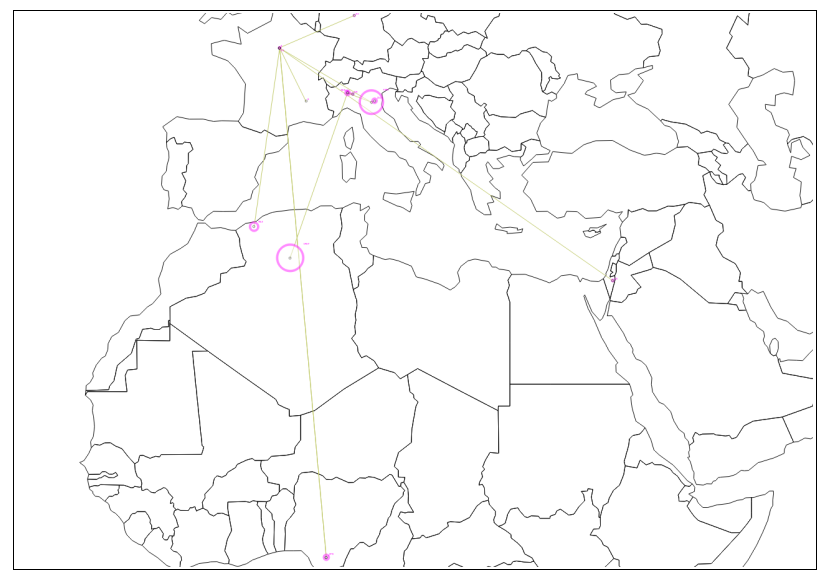

Figure 7. IG of a bread supply chain, average italian practice. The nodes map the amount of non-renewable primary energy used per person in a year $(\mathrm{MJ} /$ person * year) and refers to the consumption of $41,7 \mathrm{~kg}$ of bread (Magentino-Abbiatense context) 


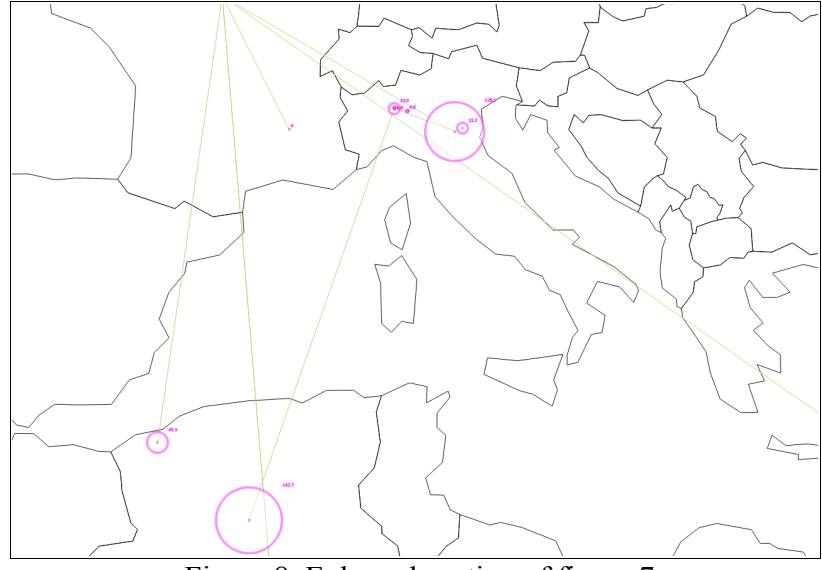

Figure 8. Enlarged portion of figure 7

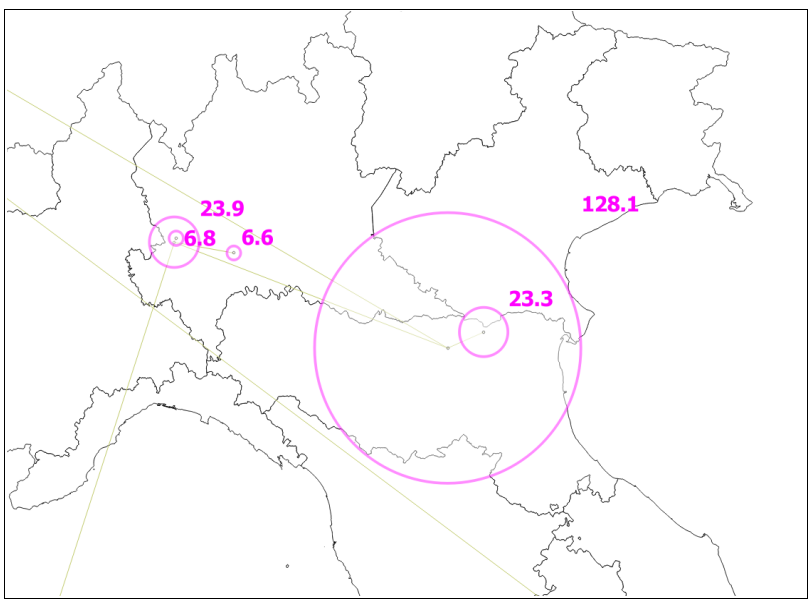

Figure 9. Enlarged portion of figure 7

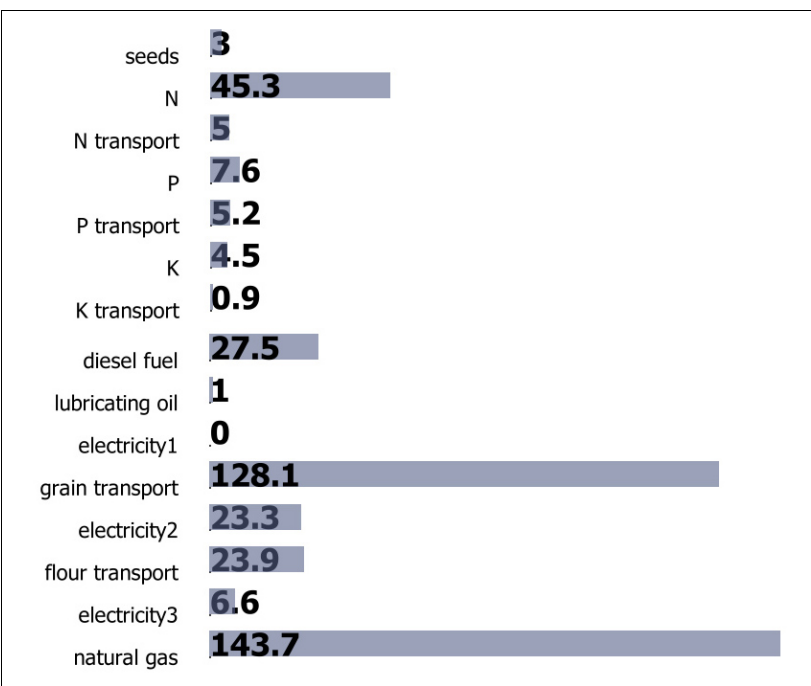

Figure 10. Amount of non-renewable primary energy (MJ / person * year) associated with a bread supply chain, average Italian practice, $41,7 \mathrm{~kg} /$ person*year (Magentino-Abbiatense context)

2.7 How to use the IGs to develop scenarios, or to assess / weigh the possible transfer of good practices

Each type of supply chain identifies with its own code (currently 1 to 43) a group of supply chains associated with the same product. They may have very different characteristics depending on the context and activities useful for their production / consumption / disposal. Each chain is characterized by information about the inventory data associated with their main phases, the references and the methods of calculation (available in www.oloss.net), and two reference shapefile relating to the nodes and connections, freely downloaded from the website.

Since the information is associated with a unitary quantity of product, it is possible to choose among the best practices the one best suited to the context of the scenario and, later on, multiply the values for the quantities inherent to the demand of the context under study. The connections layer allows to identify the different weight of transport due to the relocation in the scenario of the good practices chosen.

\subsection{Example applied to the housing category}

In the case of the supply chain types chosen as examples, at present, the database gathers two supply chain practices by type. Regarding the energy to heat dwellings, the information in oloss.net refer to the natural gas supply chain imported into Italy, and to the poplar wood chips supply chain grown in northern Italy.

The first is useful for mapping current consumption practices, natural gas is in fact the main source of energy used for heating buildings, and Algeria is one of the main exporters towards Italy. The second is one of the possible good transferable practices for the development of scenarios. Figure 11 shows a map of this same practice transferred to the area adopted as a case study to develop scenarios, in the province of Milan. In this case the elaborations made in the transfer procedure consist in multiplying the data associated to the supply chain by the total contribution per person related to the context taken in analysis and repositioning the nodes, changing and recalculating the energy costs for transport associated with the connection vectors.

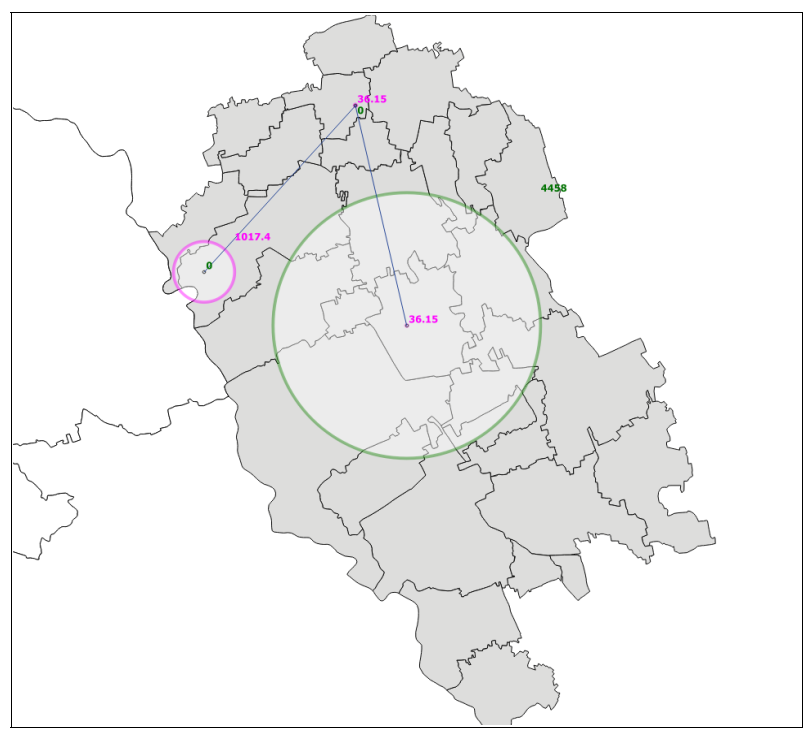

Figure 11. Impact Geography related to a good practice of renewable energy use, supply chain type "housing heating", poplar wood chips locally grown, MJ / person * year

(Magentino-Abbiatense context) 


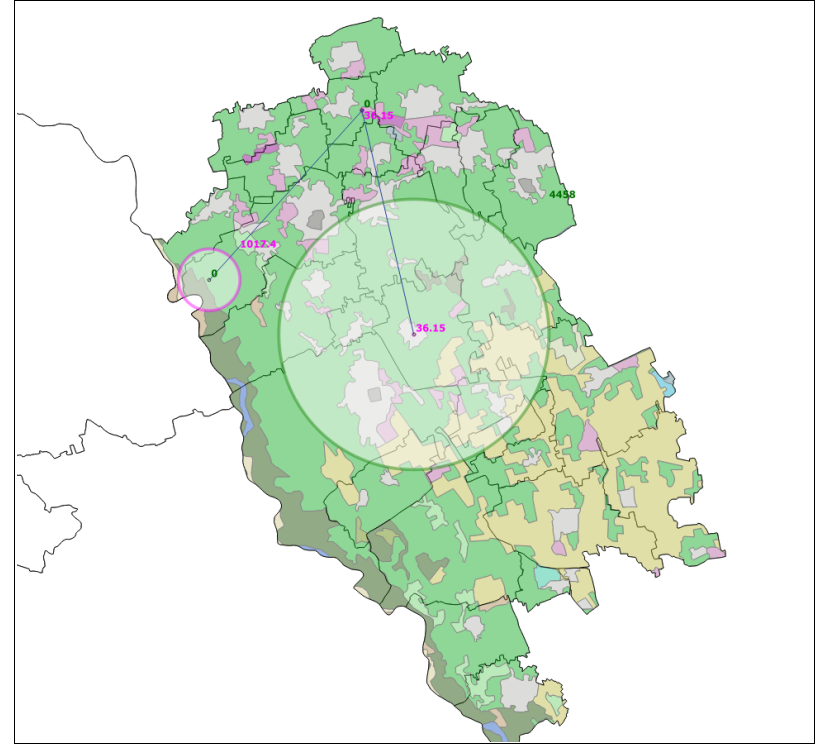

Figure 12. Same IG presented in Figure 11, in the background, map of land use types (biomass availability among Resources Geographies).

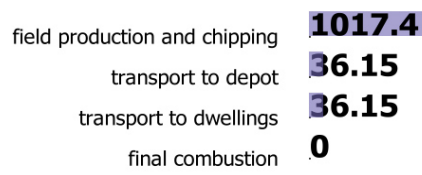

Figure 13. Amount of non-renewable primary energy associated with the nodes practice concerning the use of the local poplar woodchips for housing heating, MJ / person * year (MagentinoAbbiatense context).

\begin{tabular}{|rl|}
\hline field production and chipping & $\mathbf{0}$ \\
transport to depot & $\mathbf{0}$ \\
transport to dwellings & $\mathbf{0}$ \\
final combustion & $\mathbf{4 4 5 8}$ \\
\hline
\end{tabular}

Figure 14. Amount of renewable primary energy associated with the nodes practice concerning the use of the local poplar woodchips for housing heating, MJ / person * year (MagentinoAbbiatense context).

\subsection{Example applied to the food category}

In the case of the bread supply chain, the two practices in the database are related to the production of non-organic flour bread representing the common Italian practice, and the production of organic bread in the Po Valley of the Lombardy Region.

As in the previous case the first is useful to describe the current demand in the place chosen for the scenario. The data in the IGs were multiplied by the amount representative of the annual bread average consumption per person in Italy (ISTAT, 2012).

The second can be used to verify the effectiveness of the adoption of a good practice with reduced environmental impact. Also in this case the data associated to the supply chain were multiplied by the representative quantities of the annual average consumption and the distance between the nodes was calculated on the basis of the maximum dinstance between the farthest points of the context chosen as local.

\subsection{Potential offered by GIS in scenarios development}

Once the good practices have been transferred or revised in scenarios (oriented to the reduction of environmental impacts and to the increase of the self-sustainability of established communities), it will be possible to use the mapped data in different ways according to the possible interaction between different types of maps:

- identification of suitable catchment areas;

- interactions between resources geographies and IGs;

- $\quad$ interaction among IGs.

\subsection{Identification of suitable catchment areas}

The cohabitation in the same GIS of data related to factors that infuence the demand and data related to the specific supply chains make it possible to identify catchment areas suitable for the good practices transfer. Depending on the type of practice, its transfer presupposes the presence of a possible local demand that could constitutes an adequate critical mass.

In the case of the energy for housing heating, a preliminary mapping of the factors that influence the energy needs (average surface area per inhabitant, form factors, age range of the buildings)(ISTAT, 2012) enable to map the differentiated energy demand of the context under analysis.

This data accessibility allows, first, to identify the availability to spend of the settled community and secondly, based on the concentration of energy loads, to understand the real feasibility of transferring more complex practices, such as cogeneration systems with district heating.

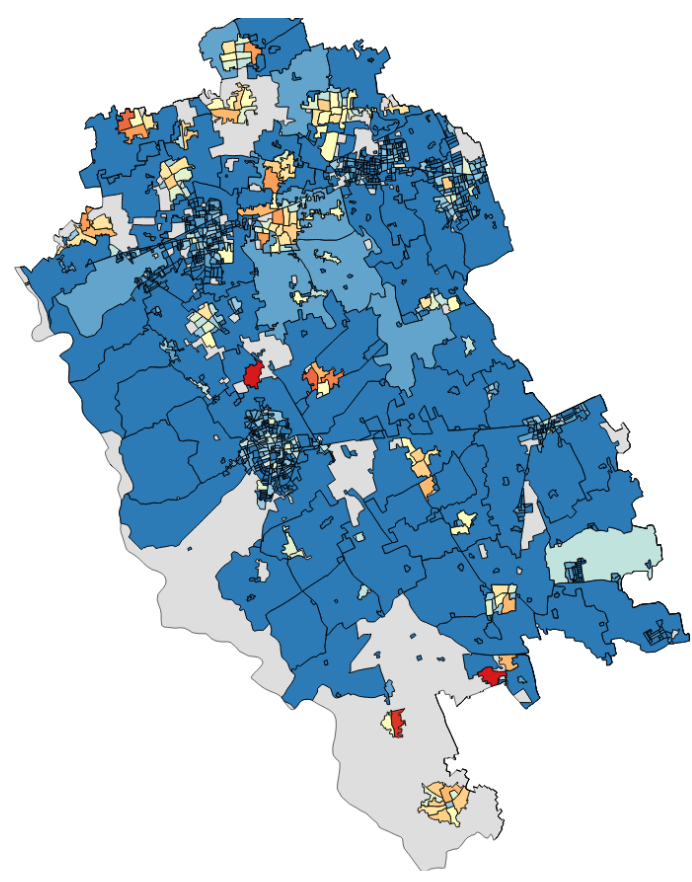

Figure 15. Map of the willingness to pay for home heating (€/year) (Magentino-Abbiatense context) 


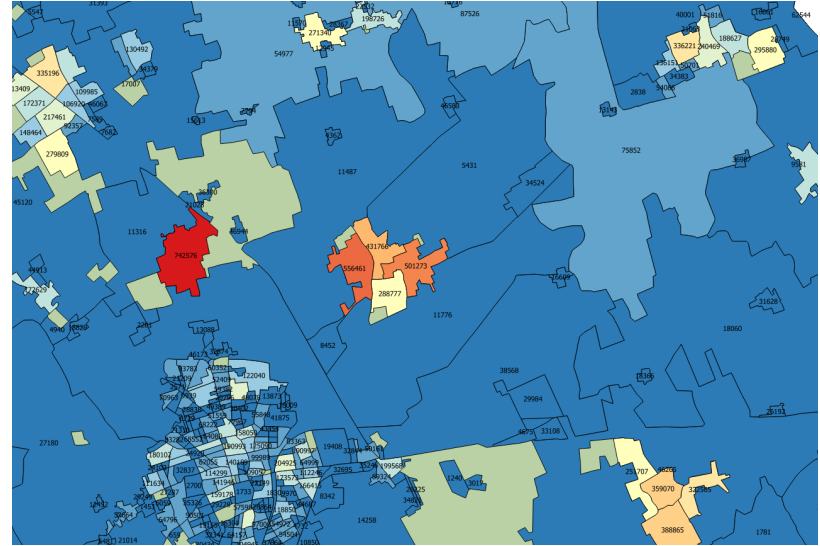

Figure 16. Excerpt from the map of the willingness to pay for home heating ( $€$ /year) (Magentino-Abbiatense context)

\subsection{Interactions between resources geographies and IGs}

The association to nodes of the main energy and material flows, allows to operate directly on the data stored in each node of the chain to assume ameliorative theoretical solutions, oriented towards a greater use of local renewables.

If the solar irradiation mapping (among Resources Geographies) shows adequate irradiation conditions, it is possible to assume the local production from solar sources (photovoltaic systems), for those activities that involve an electric energy consumption. The georeferencing of several good practices, and the association of information with unitary quantities enable to create an hypothetical practice by composing more good practices among them. The same thing can happen assuming to replace the non renewable energy costs for the production in the field, mainly the diesel fuel, with locally produced vegetable fuels (only if the Resource Geographies would show an adequate availability of this type of productive land). In this case, an increase in the use of local renewables would correspond to the increase in local productive land use.

\subsection{Interaction among IGs}

In local self-sustainability scenarios most of the supply chain practices are located in the same territorial area. This allows to trigger optimization processes using waste or scraps from one supply chain as resources for another. For example, the supply chain of bread, in the node related to the field production of grain quantifies the emission of straw. It can be intercepted by the housing category as a possible source of energy (electrical, thermal or cogeneration) or as a building material for the creation of insulating panels.

The supply chain of local organic bread requires incoming flows for field production, as organic fertilizers. In this case it is possible to activate connections with animal production chains that account the dung among their output. The same can concern the supply chains of organic waste from the housing compounds, as possible outputs of suitable compost production for organic cultivations.

\subsection{Future database implementation procedures}

The database its actually populated with a limited amount of production and consumption chains. It gives the possibility to identify a common standard of georeferenced data suitable for a database developed and implemented by an open community. The long-term goal is to involve different research fields that share the same development goals.

Every year a report publication on the database state of progress is expected, it will correlate the georeferenced supply chains downloadable from the website with data sources and the authors references.

\section{REFERENCES}

Clementi M., Scudo G., 2013. Representing local selfsustainability. In: Envisioning Architecture Design, Evaluation, Comunication, Morello E., Piga B. EAEA11-2013 Conference Proceedings, Milano.

ISTAT, Italian National Institute of Statistics, 2012. Data warehouse. Available at : www.istat.it

Sale K. 1985. Dwellers in the Land. The Bioregional Vision, Sierra Club Books.

Scudo G., Clementi M.: Bioregion and Ecoefficiency. In: Periurban areas and food-eenrgy-water nexus. Sustainability and resilience strategies in the age of climate, Magoni M. et al. , Springer 2016. 